\title{
Louise de Savoie, 1476-1531, P. Brioist, L. Fagnart et C. Michon (dir.)
}

\section{Maria Colombo Timelli}

\section{(2) OpenEdition}

1 Journals

\section{Édition électronique}

URL : http://journals.openedition.org/studifrancesi/10532

DOI : 10.4000/studifrancesi. 10532

ISSN : 2421-5856

Éditeur

Rosenberg \& Sellier

\section{Édition imprimée}

Date de publication : 1 décembre 2017

Pagination : 535-536

ISSN : 0039-2944

\section{Référence électronique}

Maria Colombo Timelli, «Louise de Savoie, 1476-1537, P. Brioist, L. Fagnart et C. Michon (dir.) », Studi

Francesi [En ligne], 183 (LXI | III) | 2017, mis en ligne le 01 février 2018, consulté le 22 janvier 2021.

URL : http://journals.openedition.org/studifrancesi/10532 ; DOI : https://doi.org/10.4000/

studifrancesi. 10532

Ce document a été généré automatiquement le 22 janvier 2021.

\section{(c) 9 (i) $\Theta$}

Studi Francesi è distribuita con Licenza Creative Commons Attribuzione - Non commerciale - Non opere derivate 4.0 Internazionale. 


\title{
Louise de Savoie, 1476-1531, P. Brioist, L. Fagnart et C. Michon (dir.)
}

\author{
Maria Colombo Timelli
}

\section{RÉFÉRENCE}

Louise de Savoie, 1476-1531, sous la direction de Pascal BRIOIST, Laure FAGNART et Cédric MICHON, Presses universitaires François-Rabelais, Presses Universitaires de Rennes, 2015, Collection «Renaissance», 298 pp.

1 Issu d'un colloque international qui s'est déroulé à Romorantin-Lanthenay en décembre 2011, ce volume réserve une section entière à «Louise et les Lettres». Une première contribution, de Mary Beth WINN et Kathleen WILSON-CHEVALIER, fait le point sur la collection de Louise (86 ouvrages, tous en français, sauf les livres d'heures, répartis entre 58 mss et 28 livres imprimés). Basée sur les documents d'archives et sur les livres eux-mêmes, cette enquête parcourt la chronologie des acquisitions en s'appuyant sur quelques dates significatives: celle de son veuvage en 1496, puis celles de ses régences, après 1515 et entre 1524-1526. Les Auteures commentent les titres les plus représentatifs et les caractéristiques saillantes de cette bibliothèque, qui, à côté de volumes somptueux, a accueilli aussi des livres plus modestes; la question reste cependant ouverte sur la pratique réelle de lecture de la mère de François ${ }^{\mathrm{er}}$ (Louise de Savoie, ses livres, sa bibliothèque, pp. 235-252). Un deuxième article est consacré à François Demoulins, précepteur du futur roi de France, resté aux côtés de Louise lors de sa régence en 1515-1516, et enfin au service de François $\mathrm{I}^{\mathrm{er}}$ après 1517 (charlotte BONNET, Louise de Savoie et François Demoulins de Rochefort, pp. 253-262). En même temps chronique de la famille royale et chronique politique voire journal de voyage, le Journal «de Louise de Savoie» (1508-1522) fait l'objet de l'analyse de Nadine KUPERTY-TSUR, qui met l'accent, d'abord, sur le contenu de la copie conservée la plus ancienne (Paris, BnF, Arsenal 3435) et sur la part de Louise dans sa rédaction, pour examiner ensuite la fiabilité des éditions, qui-après celle de Samuel Guichenon (1660)-ont détruit la 
structure originelle du Journal, organisé en 12 sections correspondant aux 12 mois de l'année (Le "Journal" de Louise de Savoie: nature et visées, pp. 263-276). Un dernier article porte sur la nouvelle 19 de l'Heptaméron, située à Mantoue, et essaie de confronter deux cultures - celles de la Renaissance italienne et française - et deux femmes, Marguerite et Isabelle, protagonistes chacune à sa manière $\mathrm{du} \mathrm{xvI}^{\mathrm{e}}$ siècle français (Romano NANNI, Au temps d'Isabelle: en relisant l"'Heptaméron" de Marguerite, pp. 277-288). 